\title{
Strategies to decrease the rate of preventable readmission to hospital
}

\section{Norbert Goldfield MD}

Previously published at www.cmaj.ca

$\infty$ See related research article by van Walraven and colleagues, page 551

$\mathrm{I}$ $\mathrm{n}$ developing a tool to predict early death and unplanned readmissions to hospital, van Walraven and colleagues point to the fact that readmissions are expensive, common and often preventable, as others have stated. ${ }^{1-3}$ The rates of hospital readmission can be important indicators of quality of care. ${ }^{4}$ They have joined mortality and complication rates as promising quality outcome measures that do not require intensive chart review, and can therefore be used to screen large numbers of records and provide a basis for comparing measures of hospital performance. ${ }^{5,6}$

Four strategies can be used to sustain a decrease in preventable readmissions to hospital:

- Use a tool to identify preventable readmissions to hospital.

- Implement a strategy to improve quality to decrease the number of readmissions.

- Use payment incentives to encourage the commitment of hospital staff and primary care physicians to decreasing the rate of readmission.

- Publicly report any information relevant to hospital readmissions.

These strategies, promoted by the Institute for Health Improvement, have been implemented by many countries. ${ }^{7}$ Industrialized countries, in particular, have used financial incentives to improve quality and stabilize costs, especially as a consequence of successful experience with tools such as Diagnosis Related Groups, first in the United States and subsequently in many other countries, including Canada. ${ }^{8}$

The LACE Index is one of several tools that can help identify preventable readmissions to hospital. ${ }^{9-14}$ Two types of tools have been developed. The mathematical (typically logistic regression) model uses data to identify factors that may predict readmission. The categorical model uses clinical logic to determine the likelihood that readmission is potentially preventable combined with subsequent validation of the data.

In the US, several tools are being used for public reporting, payment incentives and strategies to improve quality (the Center for Medicare and Medicaid Services tool, the Potentially Preventable Readmissions tool, which I helped develop, and the United Health Care tool). The Canadian, New Zealand and Australian governments have used the 30-day readmission rate as a quality indicator of hospital services. ${ }^{15,16}$ Countries that use a categorical model can identify variations

\section{Key points}

- Hospital readmissions are expensive, common and often preventable.

- The LACE Index can be used with several other existing tools to identify preventable readmissions.

- A multidisciplinary approach, ranging from strategies to improve quality to payment incentives, may be needed to sustain a decrease in the number of readmissions.

in patterns of readmission practice without extensively recalibrating and validating the tool.

Several issues should be considered when developing a tool to identify preventable readmission to hospital, particularly when defining what is, in fact, preventable. For example, a person's admission to hospital for an appendectomy after a previous hospital stay for congestive heart failure is clearly not preventable. As with the United Health Care measure, the LACE Index uses an all-cause readmission approach - that is, all readmissions are considered preventable.

The developers of LACE emphasize that hospitals must be able to replicate the index. However, as is the case with the Center for Medicare and Medicaid Services measure, hospitals cannot easily replicate the LACE Index because it requires information that is inaccessible to the hospital (e.g., identification of a patient's past visits to the emergency department). The developers of the LACE Index found that severity of illness (as specified by the Charlson Index) is critical for comparing preventable readmissions. They may want to consider other variables, such as serious mental health and substance abuse disorders, that may not be completely represented in the Charlson Index.

In the development of such tools, one needs to distinguish clinical variables from those that are, at least partly, under the control of the health care system. For example, longer length of hospital stay can certainly correlate with severity of illness, but it may also reflect hospital inefficiency. In addition, in a

Norbert Goldfield is the medical director of 3M Health Information Systems Inc. in Wallingford, USA.

CMAJ 2010. DOI:10.1503/cmaj.100243

All editorial matter in CMAJ represents the opinions of the authors and not necessarily those of the Canadian Medical Association. 
geographic area where primary care, home care and coordination of health services are less than optimal, the number of visits to an emergency department and subsequent readmission to hospital will be higher than desirable, but this represents inadequate services rather than inherently sicker patients.

Once providers and clinicians have decided on an appropriate tool, the other three strategies for reducing the rate of readmission to hospital can be implemented simultaneously or sequentially. Researchers and practitioners have developed several interventions, broadly defined as administrative and clinical, that will improve quality by decreasing the rate of readmission; the positive impact of such interventions has been well documented. ${ }^{17,18}$ From an administrative perspective (e.g., discharge planning), the health care community is increasingly able to understand and improve a patient's ability to manage in the home environment. ${ }^{19}$ From a clinical point of view, a patient's worsening condition in hospital may not be recognized; unfortunately, particularly in this cost-conscious era, discharge can be ordered too early. ${ }^{20}$

An internally focused strategy to improve quality is necessary but insufficient to systematically lower rates of readmission to hospital. Payment incentives and public release of information must be combined with information that can increase confidence of patients, families and consumers in dealing with the challenges that readmissions pose. In nearly every country, there is little financial incentive to decrease rates of readmission to hospital, and without such incentive, there will be no substantive effort by hospitals and primary care physicians to do so.

What payment incentive is reasonable? The payer has to pay for most of the costs incurred in a readmission or risk creating access problems. In designing a modest payment incentive that will encourage health professionals to become interested, it is important (in the US context of a payment system in which hospitals are paid on a per-hospital discharge basis) to distinguish between a case-specific approach and a ratebased approach. With a case-based approach, any financial incentive to decrease the rate of readmission is applied to a specific patient whose readmission was potentially preventable. With a rate-based approach, hospitals with a higher rate of readmission, when compared with best practice patterns (severity and clinically adjusted) in a geographic region, have a decrement in payment for all readmissions. The savings generated from a rate-based approach can be used as a bonus to high performing hospitals, to provide grants to lowest performing hospitals to improve their readmission processes, and as additional payment to primary care physicians who can demonstrate successful coordinated care. ${ }^{21}$

All of us, including consumers and health care professionals, deserve publicly available comparative information on rates of hospital readmission such as that available in the state of Florida (www.floridahealthfinder.gov/). Such information should, to be fair to the admitting hospital, include readmissions to any hospital. It is well known that public reporting can influence decision-making by consumers. ${ }^{22}$
As we continue to learn about best practices on public reporting and the other strategies summarized in this commentary, health care professionals and consumers, including policymakers, must confront the challenge of decreasing rates of readmission to hospitals.

Competing interests: The author is the lead clinical developer of all classification tools at 3M Health Information Systems Inc.

\section{REFERENCES}

1. Van Walraven C, Dhalla IA, Bell C, et al . Derivation and validation of an index to predict early death or unplanned readmission after discharge from hospital to the community. CMAJ 2010 Mar. 1 [Epub ahead of print]

2. Medicare Payment Advisory Commission. Payment policy for inpatient readmissions. In: Report to the Congress: promoting greater efficiency in Medicare. June 2007. Washington (DC): The Commission; 2007. Available: www.medpac.gov /chapters/Jun07_Ch05.pdf (accessed 2010 Feb. 9).

3. Jencks SF, Williams MV, Coleman EA. Rehospitalizations among patients in the Medicare fee-for-service program. N Engl J Med 2009;360:1418-28.

4. Friedman B, Basu J. The rate and cost of hospital readmissions for preventable conditions. Med Care Res Rev 2004;61:225-40.

5. Calver J, Brameld KJ, Preen DB, et al. High-cost users of hospital beds in Western Australia: a population-based record linkage study. Med J Aust 2006;184:393-7.

6. Westert GP, Lagoe RJ, Keskimaki I, et al. An international study of hospital readmissions and related utilization in Europe and the USA. Health Policy 2002;61:269-78.

7. Institute for Healthcare Improvement. How do they do that? Low-cost, high-quality health care in America. Cambridge (MA): The Institute; 2009. Available: www.ihi.org/IHI/Programs/StrategicInitiatives/HowDoTheyDoThat.htm (accessed 2010 Mar. 4)

8. Russell LB. Medicare's new hospital payment system: Is it working? Washington (DC): Brookings Institution; 1989.

9. PacifiCare Inpatient Hospital Readmission Index Methodology. Salt Lake City (UT): PacifiCare; 2007. Available: www.uhc.com/live/uhc_com/Assets/Documents /UnitedHealth\%20Group\%2030-day\%20All-Cause\%20Readmission.pdf. (accessed 2010 Feb. 10)

10. Keenan PS, Normand SL, Lin Z, et al. An administrative claims measure suitable for profiling hospital performance on the basis of 30-day all-cause readmission rates among patients with heart failure. Circ Cardiovasc Qual Outcomes 2008;1: 29-37.

11. Goldfield NI, McCullough EC, Hughes JS, et al. Identifying potentially preventable readmissions. Health Care Financ Rev 2008;30:75-91.

12. Billings J, Dixon J, Mijanovich T, et al. Case finding for patients at risk of readmission to hospital: development of algorithm to identify high risk patients. BMJ 2006;333:327

13. Donnan PT, Dorward DWT, Mutch B, et al. Development and validation of a model for predicting emergency admissions of the next year (POENY). A UK historical cohort study. Arch Intern Med 2008;168:1416-22.

14. Bottle A, Aylin P, Majeed A. Identifying patients at high risk of emergency hospital admissions: a logistic regression analysis. J R Soc Med 2006;99:406-14.

15. Health indicators. Ottawa (ON): Statistics Canada; 2004.

16. NHMBWG (National Health Minister's' Benchmarking Working Group). First national report on health sector performance indicators: public hospitals - the state of play. Canberra (Australia): Australian Institute of Health and Welfare; 1996.

17. Project RED Training Manual. Boston (MA): Boston University Medical Center. Available: www.bu.edu/fammed/forms/projectred/index.html. (accessed 2010 Mar. 3).

18. Jack BW, Chetty VK, Anthony D, et al. A reengineered hospital discharge program to decrease rehospitalization: a randomized trial. Ann Intern Med 2009; $150: 178-87$.

19. Shepperd S, McClaran J, Phillips CO, et al. Discharge planning from hospital to home [review]. Cochrane Database Syst Rev 2010;(1):CD000313.

20. Giordano A, Scalvini S, Zanelli E, et al. Multicenter randomised trial on homebased telemanagement to prevent hospital readmission of patients with chronic heart failure. Int J Cardiol 2009;131:192-9.

21. Averill RF, McCullough EC, Hughes JS, et al. Redesigning the Medicare inpatient PPS to reduce payments to hospitals with high readmission rates. Health Care Financ Rev 2009;30:1-15.

22. Hibbard JH, Stockard J, Tusler M. Hospital performance reports: impact on quality, market share, and reputation. Health Aff (Millwood) 2005;24:1150-60.

Correspondence to: Dr. Norbert Goldfield, medical director, $3 M$ Health Information Systems Inc., 100 Barnes Rd. Wallingford MA 06492,USA; nigoldfield@mmm.com 